the winds, temperatures, and barometrical indications might have been added for the like reason.

13. Table XI. also requires a note of the season of the year and the number of days of observations. It may here be asked, how is the discrepancy to be reconciled between the lessening of ozone as you sail to the Polar Regions, and the increase of ozone as you ascend in the air, when the temperature as regularly falls in the one case as in the other.

14. The records showing the connection between phosphorescence and manifestation of ozone are very satisfactorily drawn out, and may probably become of much value in a new investigation.

15. The less prevalence of ozone in the higher extratropical latitudes may be due, as suggested in another case, to the dryness of the atmosphere impairing the sensitiveness of the test papers, so that for the present such deductions are under suspicion.

I6. The idea that the prevalence of ozone is coincident generally with a low barometer seems well supported by the observations recorded, but some explanation will be required to account for its maximum occurrence with south-east zvinds in Tables IX. and XI., if one should accept the theory of its connection only with equatorial winds.

17. That its presence may be connected with warm temperatures of the air seems better established at sea than on land, as also its coincidence with humidity of the air, though this is somewhat vitiated by the conscientious suggestion that its manifestation may be due to the increased susceptibility of the test-papers when moist.

I8. In the statement that ozone increases as you ascend mountainous elevations, it is not stated what winds were blowing at the time, which would appear to be necessary, if the idea of its prevalence with any particular wind were considered essential.

19. The key to the origin and prevalence of ozone in the atmosphere seems still undiscovered, and we do not yet appear to have determined if it belungs to aqueous vapour or a special wind, or whether it be an additional constituent of the air, like carbonic acid, or a floating entity, like a cloud.

NuBIBus

\section{The Limits of the Gulf Stream}

As one of those engaged in the compilation of the Atlantic pilot-charts published by the Admiralty, on which are given the limits, velocity, and general features of the Gulf Stream, as well ns the boundaries of the regions in which ice and icebergs may be fallen in with in the North Atlantic, I cannot allow the letter in NATURE (vol. ix. p. 343), by W. W. Kiddle, of the White Star Mail steamship Oceanic, to remain unchallenged.

The Gulf Stream and ice boundaries, delineated on the North Atlantic chart, referred to in that letter, are in their details transcripts from the Atlantic pilot-charts.

These details were the result of much patient investigation, and obtained from many sources probably unknown to Captain Kiddle; among the most valuable were the painstaking and sound observations made by members of the United States Coast Survey, and to be found embodied in the annual reports between 1843 and 1859 ; and especially from the exhaustive and learned work on currents, so well known to cultivators of nautical science, by the late Major Rennell.

If the average boundaries of the Gulf Stream cannot be laid down within reasonable limits from the authorities I have quoted, aided, too, by the many observations of ships of war, extending over the present century, I fear that Captain Kiddle's results will not assist us in a more accurate delineation.

It is, however, to be hoped that Captain Kiddle's information on the currents may be more reliable than that he has ventured upon giving with regard to the limits of iceherg-drift ; here recorded facts are irresistibly against him. He has only to consult any North Atlantic memoir on the subject, and he will find that icebergs have been fallen in with so far south as $36^{\circ} 10^{\prime} \mathrm{N}$., or $7^{\circ}$ south of the high authority he quotes. I would refer him on this interesting subject, as well as how icebergs are found on the southern edge of the Gulf Stream, and why it is possible "that bergs could drift square across the heated waters of the Gulf Stream to lat. $39^{\circ}$ N.," to a paper by the well-known W. C. Redfield, of the United States (reprinted in the Nautical Magazinetor 1845 ), who gathered the facts that have simply been utilised in the Admiralty charts.

London, March II

Thomas A. Hull

\section{The Great Ice-Age}

MR. GREen, reviewing Mr. J. Geikie's work on the "Great Ice-Age" (NATURE, vol. ix. p. 318), expresses the opinion that a glacial period must have been one of intense cold. This is the general opinion, and yet I think it can be shown to rest on a misconception. If the climate at any given elevation is cold enough to form glaciers, no decrease of the winter temperature will increase their magnitude; while on the other hand a low summer temperature is shown by the facts of physical geography to be eminently favourable to glaciation. This last may almost be called an identical proposition, for permanent snow means snow which lasts through the summer.

As Mr. Croll has pointed out, there have been periods where the sun's greatest and least distances were respectively greater and less than now. He thinks that a glacial period occurred when, in the course of the precession of the equinoxes, the sun's greatest distance occurred in the winter, so as to cause a cold winter. I think the true theory of the glacial climate is exactly the reverse of this: that is to say, it was caused by the cold summer which occurred when the sun's greatest distance was in the summer.

I have stated these views at greater length in the fournal of the Geological Society of London, 1869, p. 350.

Old Forge, Dunmurry, Co. Antrim,

March \&

\section{J. J. MuRphy}

\section{Mars}

IN a most interesting article on the planet Mars, in your issue of NATURE for Feb. 19, which has just been shown to me, the Rev. T. W. Webb directs attention to the question of the colours of Mars being due to effects of contrast or not, and says-"Nor does it seem to have been noticed that no effect of contrast has been traced in the Polar snows."

Kindly permit me to inform $\mathrm{Mr}$. Webb that, in a paper on Mars in the last volume of the "Monthly Notices of the Royal Astronomical Society," I expressly state that, "on May I4, I873, the south Polar ice appeared (in an 8x-inch silvered glass reflector, by Browning) of quite a pale sky-blue colour, evidently by contrast," and I may add that this effect I noticed also on two or three subsequent occasions.

Burton-on-Trent, March 12

EDWARD B. KNOBEI

\section{POLARISATION OF LIGHT*}

VI.

MENTION was made in the previous article of the bands produced in the spectra of polarised light. Beside the fact of the existence of these bands it has been found upon examination that the state of polarisation at different parts of the interval between two successive bands varies; and such an examination may be made by means of a quarter-undulation plate or a Fresnel's rhomb.

If we carefully examine the spectrum of light which has passed through a selenite, or other ordinary crystal, we shall find on turning the analyser that, commencing with two consecutive bands in position, the parts occupied by the bands and those midway between them are planepolarised, for they become alternately dark and bright; while the intermediate parts, i.e. the parts at one-fourth of the distance from one band to the next, remain permanently bright. These are, in fact, circularly polarised. But it would be incorrect to conclude from this experiment alone that such is really the case, because the same appearance would be seen if those parts were unpolarised, i.e. in the condition of ordinary light. And on such a supposition we should conclude, with equal justice, that the parts on either side of the parts last mentioned (i.e. the parts separated by one-eighth of the interval between two bands) were partially polarised. But if we introduce a quarter-undulation plate between the selenite and analyser, with its axis inclined at $45^{\circ}$ to that of the selenite, circular polarisation will be converted into plane and plane into circular. This being so, the parts which

$$
\text { * Continued from p. } 326 \text {. }
$$

